\title{
Evidence for airborne infectious disease transmission in public ground transport - a literature review
}

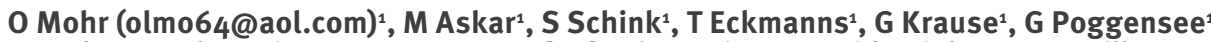

1. Robert Koch Institute, Department of Infectious Disease Epidemiology, Surveillance Unit, Berlin, Germany

Citation style for this article:

Mohr O, Askar M, Schink S, Eckmanns T, Krause G, Poggensee G. Evidence for airborne infectious disease transmission in public ground transport - a literature review. Euro Surveill. 2012;17(35):pii=20255. Available online: http://www.eurosurveillance.org/ViewArticle.aspx?Articleld=20255

Article submitted 24 July 2011 / published on 30 August 2012

While guidelines on contact tracing (CT) after exposure to certain infectious pathogens during air travel exist, no guidance documents are available on CT in response to potential exposure on public ground transport. We reviewed scientific and non-scientific literature on transmission of airborne pathogens in public ground transport and on factors potentially influencing transmission. We identified 32 relevant publications (15 scientific and 17 non-scientific). Most of the selected studies dealt with transmission of tuberculosis. However, the relation between travel duration, proximity to the index case and environmental factors, such as ventilation, on disease transmission in public ground transport is poorly understood. Considering the difficulty and probably limited effectiveness of CT in ground transport, our results suggest that only exceptional circumstances would justify CT. This contrasts with the high level of attention CT in air travel seems to receive in international regulations and recommendations. We question whether the indication for CT should be revisited after a risk-benefit assessment that takes into account exposure in both ground and air transport.

\section{Introduction}

Passengers using public transport may be at risk of infectious disease when they are exposed to infected passengers. Although guidelines on contact tracing (CT) after exposure to selected airborne infectious diseases during air travel exist, no guidance documents are available on CT in response to potential exposure on public ground transport. Comparing the share of performance of air and ground travel respectively, the share of performance in public ground transport, such as buses/coaches, trams, metros and railways, of total transport performance of passengers in Europe in 2007 was nearly twice as high $(15.7 \%)$ as the share of air transport performance $(8.8 \%)[1,2]$.

CT is defined as the identification of persons who may have been exposed to an infectious disease by an infected person and ensuring that they are aware of their exposure $[3,4]$. Although a recent literature review concentrated on published studies on tuberculosis (TB) transmission and recommendations for $\mathrm{CT}$ related to use of public transport [5], our review was carried out to analyse available publications on the evidence for transmission of any airborne infectious disease and on factors potentially influencing the risk of transmission in public ground conveyances. In addition to searching the scientific literature, we also performed a search of non-scientific literature.

\section{Methods}

\section{Search strategy}

Scientific literature

In May and June 2009, a review of scientific literature was carried out using Scopus, the largest abstract and citation database of peer-reviewed literature and highquality web sources $[6,7]$. It provides $100 \%$ MEDLINE coverage and contains more than 19,500 titles from 5,000 publishers [8]. We searched the database for mentions of airborne transmission of infectious diseases in public ground conveyances. We decided to perform the broadest possible search to include publications that might touch upon airborne disease transmission and CT without necessarily being the paper's main subject. Through the 'all fields' search, the following keywords were used: 'railway', 'train', 'bus', 'school bus', 'coach', 'tram', 'tramway', 'metro', 'subway', 'underground' and 'tube'. We combined each means of public ground transport keyword with each of the following keywords (through 'AND'): 'infection', 'infectious disease', 'transmission', 'contact tracing', 'contact investigation', 'passenger tracing', 'tuberculosis', 'mycobacterium tuberculosis', 'TB', 'meningitis', 'meningococcal disease', 'avian influenza', 'viral hemorrhagic fever', 'SARS', 'bubonic plague', 'rubella', 'Lassa fever', 'measles', 'diphtheria' and 'smallpox'. In early December 2010, we updated the search using the identical keywords through the 'all fields' search.

In a first step, search hits were screened by three reviewers: articles were selected if they contained information on airborne infectious disease transmission in public ground transport. English titles of all the selected publications were reviewed. If the title information was insufficient, the abstract was looked at to decide if the publication potentially met the selection criterion. The full text of each paper was obtained 
when the selection criteria were met or when further information was needed to decide whether to include an article or not. When a reviewer was uncertain about making a decision at any of these steps, the other team members were consulted and a joint decision was taken. The selected articles were then reviewed for events of airborne infectious disease transmission in public ground transport.

The following data were retrieved from each study: publication details (year, author(s), location), means of transport, diagnostic tests, number of infected persons, number of tested contacts, transmission rate and number of cases with active disease. The publications were evaluated on factors potentially influencing transmission of infectious disease such as cumulative exposure related to repeated trips (e.g. on a school bus or commuter bus), duration of travel and environmental factors (ventilation and air conditioning systems, seating position, distance to contact person). Bibliographies of potentially relevant publications were checked for additional studies.

\section{Non-scientific literature}

In February 2009, we performed a structured search for non-scientific literature through the search engines Google News, Google Scholar, GENIOS and World News. The search was limited to English and German publications.

The search with GENIOS allowed a maximum of two keywords, the search of the World News archive was limited to the previous six months (September 2008February 2009), the World News advanced search was only searchable day by day, whereas the search with Google News archive and Google Scholar was limited to the previous five years (February 2004-February 2009). Due to the differing time frame for searches provided by the engines we decided not to update the search.

The keywords 'bus', 'railway' and 'metro' were combined with 'infectious disease'. The first 200 hits from each keyword combination with each search engine were screened to assess potential relevance to transmission of infectious disease and CT in public ground transport. We reviewed title, abstracts or both of all retrieved publications. Potentially relevant articles were selected: inclusion criteria were events or cases of potential airborne infectious disease transmission. The full text of each selected publication was obtained and evaluated.

We adopted the following definitions: an infection with Mycobacterium tuberculosis was evidenced by a positive tuberculin skin test (TST) reaction and/or a positive interferon-gamma release assay (IGRA) without any sign of clinically or radiologically manifest disease. Active tuberculosis was defined by bacteriologically, histologically or radiologically confirmed active disease. Measles was diagnosed through testing of serum specimens for measles-specific IgM and IgG antibodies using an enzyme immunoassay: persons who were $\lg M$ positive were defined to have a recent measles infection. A classical measles case was defined as a person who meets the clinical case definition and/or meets the serological criteria [9]. Mild or asymptomatic measles was defined as a recent measles infection indicated by the presence of measles IgM, but who did not meet the clinical case definition [10-12]. Meningococcal disease was evidenced through culture of blood and cerebrospinal fluid (CSF) or polymerase chain reaction (PCR) of CSF.

\section{Results}

\section{Scientific literature}

Our 'all fields' search identified a total of 21,764 hits. After screening abstracts and/or titles, 72 potentially relevant publications were identified for full-text evaluation. Finally, 15 publications were selected. All selected publications describe CT. Of the selected publications, all but one reported disease transmission in buses; the other described a combined trip by bus and train, but CT focussed solely on the passengers who travelled by train [13]. In total, 14 events, dating from 1961 to 2008, were included in our study (the same event was described by two publications). No relevant publication was found reporting on airborne infectious disease transmission in a tram or metro/underground/ subway. Of the 14 events related to airborne infectious disease transmission followed by CT in ground transport, 11 events were on TB, two on meningococcal disease and one on measles. Three reported on singular exposure during single trips and 11 on events related to cumulative exposure during repeated trips.

\section{Single-trip exposure}

Event 1, TB in train trip

A combined single bus and multiple train trips taken in January 1996 by a 22 year-old male index case with bilateral cavitation, cough and haemoptysis in the United States was reported, but CT was only undertaken for passengers who travelled by train [13]. The train journeys lasted 29.1 hours (12.3 hours from Chicago to Pittsburgh, and 16.8 hours from Washington, DC, to Florida). The median duration of travel by co-passengers was 12.3 hours (range: $1-34.7$ hours). The train operator provided a list of passengers and crew-members; the telephone number was the only available contact information. Passengers and crew members were notified via telephone (to obtain addresses) and by recorded delivery. A total of $76.8 \%$ of passengers (368/479) could be located and $50.1 \%$ of persons (240/479) were evaluated: 15 of 240 persons (6.3\%) seroconverted; of the 15 , two developed active disease. The possibility of more extensive transmission could not be excluded.

Event 2, TB in bus trip

In a single bus trip in Spain from Malaga to the Sierra Nevada in March 1998 [14], the index case was an 18 


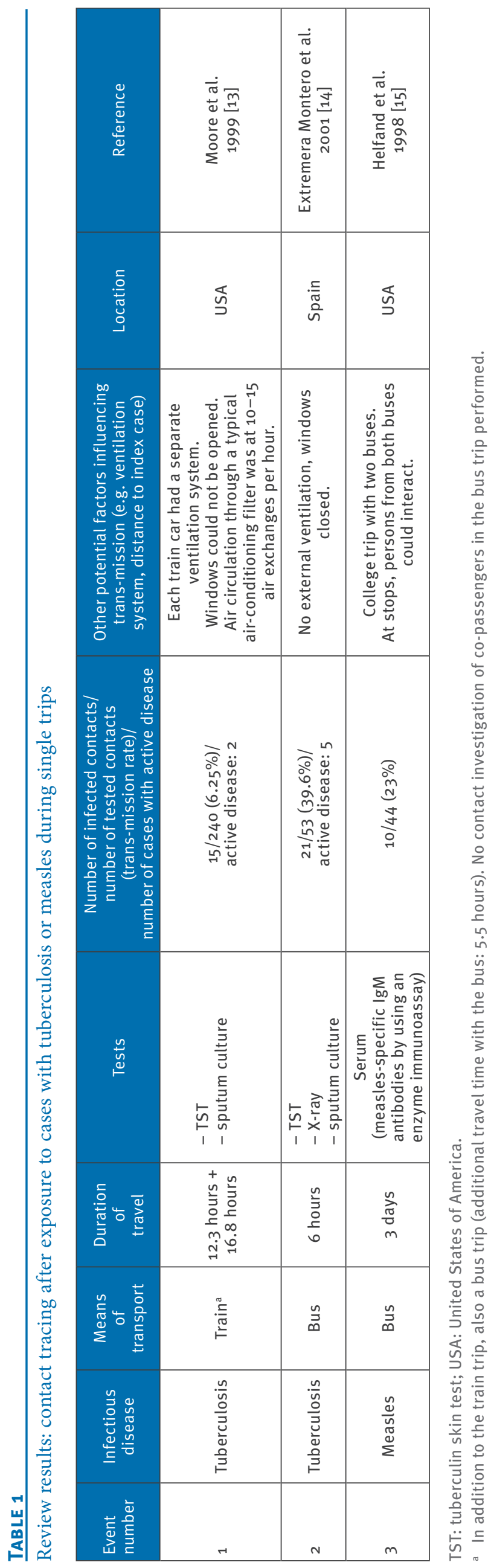

year-old male student with active TB, but without cavitations. Including the bus driver, 53 persons travelled on the bus. Two of three teachers became infected. Of the 49 students, 41 were traced: 19 seroconverted. Of these 19, five developed active disease. In total, there were 21 secondary cases. Through multivariate analysis, bus exposure was identified as an independent risk factor for TST reactivity (attributable risk: 15.9\%).

Event 3, measles in bus trip

A study in the United States investigated the frequency of mild or asymptomatic measles infections of persons exposed to a student with measles during a three-day bus trip in May 1996 involving two buses [15]. On the first day of the trip, one student became ill with clinical signs of classic measles, which was subsequently confirmed by serological studies. The exposed persons travelled on the two buses and could interact with persons on the other bus at other times, such as during meals, visits to museums and at rest stops. Most persons travelled on the same bus throughout the trip. The results demonstrated that mild or asymptomatic measles infections can occur in previously immune populations. A total of 94 persons participated in the trip: for the investigation, 45 persons agreed to participate in the study. None of the participants developed classic measles symptoms. However, 10 persons were IgM positive for measles, probably arising from exposure to the index case.

The outcome from the CT following exposure to TB or measles during a single trip are summarised in Table 1.

Repeated trip exposure

Event 4, TB in bus trip

As part of an investigation of a school- and community-based TB outbreak in late 1992 in northern Italy, independent risk factors for TST were analysed by multivariate analysis for students travelling in the same bus as the index patient [16]. The index patient was an 18 year-old student with active disease (cavitations). Out of 212 contact persons tested, 70 (33.0\%) seroconverted. The adjusted odds ratio (OR) for classroom contact was at $4.4(95 \% \mathrm{Cl}: 3.4-5.7)$ and for living in the same town was 4.8 ( $95 \% \mathrm{Cl}: 3.8-6.0)$. The OR was highest for travelling on the bus with the index patient: 5.4 (95\% Cl: 4.3-6.7). The attack rates for the bus passengers in relation to the duration of travel are shown in Table 2.

Event 5 , TB in bus trip

CT was carried out after transmission of TB on a school bus in 1998 in the United States [18]. The nine yearold index case with bilateral cavitation travelled on the school bus for 90 minutes each morning; the copassengers were exposed between 35 and 75 minutes daily. Out of 32 school bus contacts, 10 seroconverted; among those, two students developed active disease. 
Review results: daily travel time of students in two school buses in relation to attack rate (seroconversion) in tuberculosis transmission

\begin{tabular}{|c|c|c|c|c|}
\hline $\begin{array}{l}\text { Event } \\
\text { number }\end{array}$ & $\begin{array}{l}\text { Number of infected contacts/ } \\
\text { number of tested contacts } \\
\text { (transmission rate) }\end{array}$ & $\begin{array}{l}\text { Travel time } \\
\text { in minutes }\end{array}$ & $\begin{array}{l}\text { Percentage attack rate } \\
\text { (seroconversion) }\end{array}$ & Reference \\
\hline \multirow{3}{*}{4} & \multirow{3}{*}{$70 / 212(33 \%)$} & $10-20 \mathrm{~min}$ & 15.4 & \multirow{3}{*}{ Ariano et al. 1994 [16] } \\
\hline & & $25-35 \mathrm{~min}$ & 14.9 & \\
\hline & & $40 \mathrm{~min}$ & 55.0 & \\
\hline \multirow{6}{*}{10} & \multirow{6}{*}{$85 / 266(32 \%)$} & $\$ 10 \mathrm{~min}$ & 21.6 & \multirow{6}{*}{ Rogers et al. 1962 [17] } \\
\hline & & $10-19 \mathrm{~min}$ & 33.7 & \\
\hline & & $20-29 \mathrm{~min}$ & 27.0 & \\
\hline & & $30-39 \mathrm{~min}$ & 27.3 & \\
\hline & & $40-49 \min$ & 50.0 & \\
\hline & & $\geq 50 \mathrm{~min}$ & 62.5 & \\
\hline
\end{tabular}

a Travel time per trip (in most cases trip twice daily).

\section{Event 6, TB in bus trip}

A brief report described transmission of TB on a school bus in April 2007 in the United Kingdom; however, the daily duration of the bus trip was not mentioned [19]. The cumulative mean duration of exposure of students to the index case, a smear-positive 46 year-old bus driver, exceeded 24 hours. Transmission from the bus driver was extensive: 18 of the 33 students had a positive IGRA; among those, four children developed active TB.

\section{Event 7, TB in bus trip}

In the United States in 2001, of 33 passengers in a school bus exposed to the index case, 18 seroconverted. The index case was a 15 year-old student with cavitation. One of the seroconverted contacts developed active disease [20]. There was daily exposure of the contacts to the index case, but the duration of exposure was not discussed.

\section{Event 8, TB in bus trip}

In the United States in 1985, of 29 students exposed to the index case, a 13 year-old student with cavitation, 17 seroconverted; however, there was exposure in the school choir, school bus and the school itself [21]. Of the 17 students who seroconverted, eight had no other direct or indirect contact with the index patient other than on the school bus. The duration of exposure of the contacts to the index case during the bus trips was not discussed.

\section{Event 9, TB in bus trip}

CT was carried out after transmission of TB in a Japanese commuter bus in 1999 as a result of cumulative exposure to the index case through repeated trips to the workplace [22]. The index case was a 22 year-old woman without cavitation who worked as an employee of an electronics company. Of the 49 commuters exposed to the index case, five seroconverted. However, the study did not exclude workplace contacts.

\section{Event 10, TB in bus trip}

Two publications dating from 1962 reported on the same event in the United States: CT was undertaken after transmission of TB from a school bus driver (without cavitation) to students during daily trips $[17,23]$. Of 266 exposed passengers, 85 (32.0\%) seroconverted. In children riding less than 10 minutes per trip, 8 of 37 had a TST conversion. In children riding 40-49 minutes per trip, 7 of 14 children seroconverted, whereas in children following a travel time of at least 50 minutes per trip, 10 of 16 seroconverted [17] (Table 2).

\section{Event 11, TB in bus trip}

Between November 1994 and April 1995, students in two counties in New York were exposed to five school bus drivers with pulmonary TB [24]. A relative risk of 39.3 (95\% Cl: $8.8-174.8$ ) for a positive TST was significant only in students exposed to driver 3. A total of 101 students exposed to driver 3 were screened: 17 were defined as close contacts; of those, 11 were TST positive. There was no clear evidence of transmission of $M$. tuberculosis to students from drivers $1,2,4$ or 5 . No student was potentially exposed to more than one driver. However, evidence suggests that driver 3 transmitted TB not only to students, but also to bus driver 4, who developed active disease. Drivers 3 and 4 worked for the same bus company and often sat together in the closed bus of driver 3 while waiting for students to leave school and enter their buses. M. tuberculosis isolates of driver 3 and 4 were indistinguishable by DNA fingerprinting.

Event 12, TB in bus trip

A TB outbreak in an Alabama high school in the United States in 1969 led to CT of 379 persons: of 27 students 


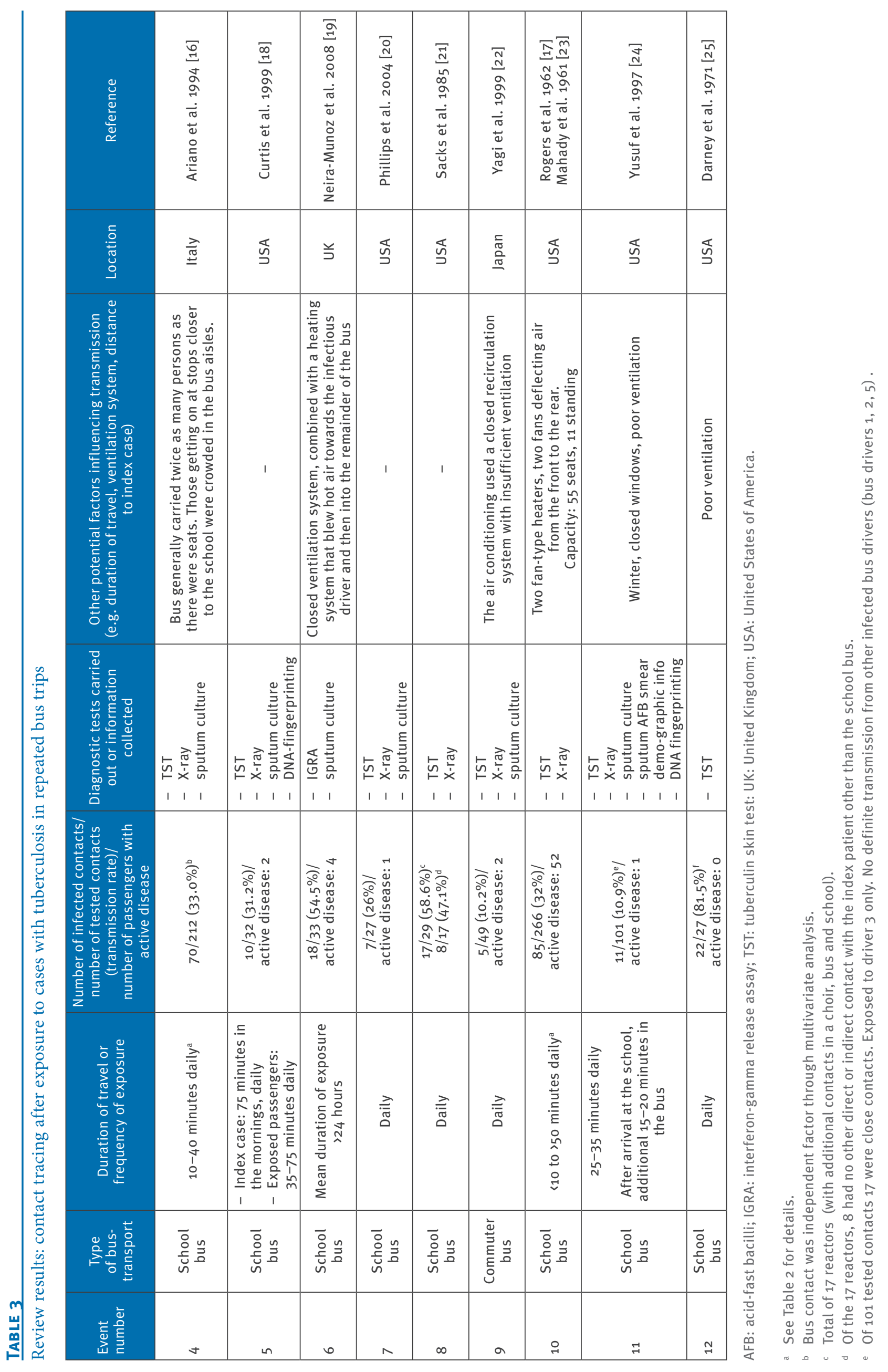


who travelled on the school bus with the index case, 22 seroconverted. The index case was a 17 year-old male in the 11th grade (ages 16-17 years). Six of the 10 positive reactors in grades 7 to $9(12-13$ years to 14-15 years) rode the bus, but only 11 of the 67 positive reactors in grades 10 to 12 (15-16 years to $17-18$ years) were bus riders. The school bus riders thus accounted for a much larger proportion of the positive reactors in grades $7-9$ than they did in grades $10-12$. The contact of the students from grades 7-9 with the index case was largely limited to travel on the school bus, which was poorly ventilated [25].

Results from CT following exposure to TB on repeated bus trips (events 4-12) are summarised in Table 3.

\section{Event 13, meningococcal disease in bus trip}

A letter to the editor described the transmission of Neisseria meningitidis (serogroup B) to two of 132 copassengers $(1.5 \%)$ in a crowded school bus in Australia in June 2005. All co-passengers were successfully traced [26].

\section{Event 14, meningococcal disease in bus trip}

In the course of a study in the United States on the effect of influenza to predispose towards meningococcal disease in 1986, five of 72 students were found to have developed meningococcal disease following exposure to the index case in a school bus [27]. The average amount of time spent on the bus the previous two weeks was 8 hours 4 minutes (cumulative) for each of the five affected children. The students had assigned seats and generally used the same seat each day. All five students reported influenza-like symptoms around 5-15 days (mean: 10.6 days) before the development of meningococcal disease. Results from CT following exposure to meningococcal disease on repeated trips on school buses (events 13 and 14) are summarised in Table 4.

\section{Non-scientific literature}

Our search of non-scientific literature yielded 55,325 hits. This search was complementary to the scientific literature search to detect information on events that might not be reflected in the scientific literature. Non-scientific sources, in the absence of any scientific peer-review process, cannot be given equal standing with the scientific literature. Nevertheless, it seemed important to check for reports in other sources given the low number of scientific publications. Of the first 200 hits from each keyword combination with each search engine, 34 potentially relevant reports were identified. Of these, we selected 17 publications dating from 1998 to 2008 on eight events - either descriptive reports of the incident followed by CT or press releases produced as part of a CT strategy. They described the potential transmission of TB, meningococcal disease, SARS or rubella during bus or railway trips. No publications on transmission of airborne infectious diseases in metros and trams were found. Only one event (event 6) picked up by the non-scientific literature search

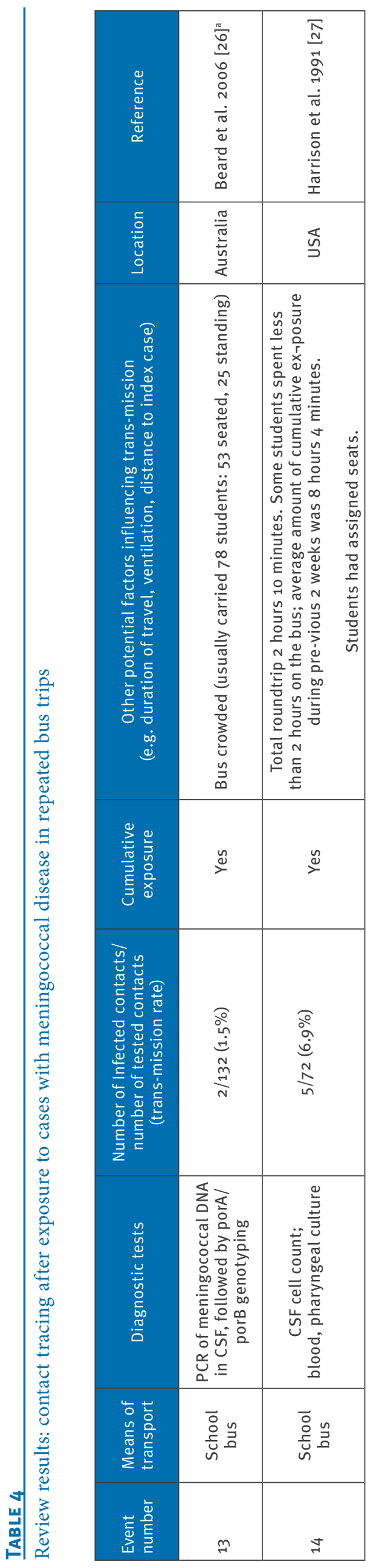

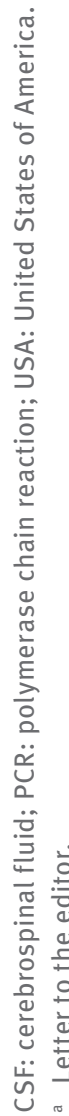


$[28,29]$ was also picked up by the scientific literature search [19].

TB in bus trips

Eight publications describe three events linked to transmission of TB as a result of bus travel. Two of those publications report on transmission of TB from a bus driver to students in the United Kingdom [28,29]. This event was also reported in the scientific literature (event 6) [19]. One of the publications describes the exposure to a bus driver infected with TB in a school bus in the United States [30]. Both school bus events are related to repeated bus trips. Five of the publications are dedicated to two different incidents in Canada concerning single-trip exposure to TB in a longdistance travel bus [31-35].

SARS in railway trip

Two publications discuss one event in a train linked to the SARS outbreak in Canada in 2003 [36,37].

\section{Meningococcal disease in railway trips}

Six publications in German newspapers describe the occurrence of meningococcal disease related to railway trips in 1998 and 2008. In 1998, three publications reported on a case of meningococcal disease on a train: an 18 year-old student became symptomatic on a railway trip from Rome (Italy) to Munich (Germany) [38-40]. On transit through Austria, co-passengers received post-exposure prophylaxis. On arrival in Germany, the train was stopped and put under quarantine. The publications did not mention whether or not the index case transmitted the disease to co-passengers on the train.

We also selected three publications from 2008 on exposure to an 18 year-old Swiss student with meningococcal disease travelling by train from Zurich (Switzerland) to Berlin (Germany) [41-43]: two of the publications were released as part of a CT media strategy: persons potentially in contact with the index case were invited to contact their local health department $[41,43]$. This event was also reported in the scientific literature [44]; however, it was not picked up by our scientific literature search, since disease transmission was not evident.

\section{Rubella in bus trip}

We selected a publication on CT in 2008 of 700 potentially exposed persons to a woman infected with rubella in a shuttle bus in the United States [45]. The woman commuted to work not knowing that she was infected.

\section{Environmental factors potentially}

influencing the risk of pathogen transmission in public ground conveyances

Of the 15 selected scientific publications, 11 contain information on potential environmental risk factors such as poor ventilation, closed ventilation systems and proximity to the index case $[13,14,16,17,19,22-27]$. The scientific publications related to the events 3,5 , 7 , and 8 and the selected non-scientific publications do not provide information on environmental factors related to pathogen transmission.

A study related to the combined bus and train trip (event 1) in 1996 in the United States describes the air circulation on the train as an air-conditioning system with filter [13]. The air exchange rate was 10-15 times per hour and filters were changed every 15 days. Windows could not be opened in any of the carriages. Each train was composed of coach cars (at least one sleeper car and one dining car). Interviews with the passengers and index TB patient indicated that transmission resulted rather from brief contact (face-to-face contact or when seated near the ill passenger while he was dining and speaking) than from extended sharing of train airspace. With the exception of a brief stay in the dining car, the index case remained seated in his assigned seat. The passenger had several episodes of haemoptysis, covered his mouth with the hood of his jacket when coughing and avoided contact with other passengers [13].

Related to a single-trip exposure of passengers to TB (event 2), poor ventilation (windows closed, no air conditioning) due to low outside temperature was reported as a factor potentially influencing transmission [14]. In total 21 persons were infected (19 students and two teachers). Of the 19 infected students, 10 were sitting no more than two rows away from the index case [14].

The TB outbreak in northern Italy (event 4) highlights that those students getting on the bus carrying the index case at the stops closer to the final destination were crowded in the bus aisles [16]. Crowding was seen as a potential factor influencing the transmission of disease in the study on an outbreak of meningococcal disease (event 13) in a school bus [26]. The publication on event 14 , reports on assigned seats for students (in general they sat in the same seat each day) in a school bus within the frame of CT related to meningococcal disease after an influenza respiratory infection [27].

The TB outbreak in an Alabama high school in 1969 (event 12) with high transmission rates especially in school bus passengers was related to poor ventilation of the bus [25]. The report of transmission of TB in a Japanese commuter bus (event 9) described a closed recirculation system with insufficient ventilation [22]. In event 6, a high transmission rate of TB was also linked to a closed ventilation system, combined with a heating system that blew hot air toward the infectious driver and then into the rest of the bus [19].

In the report from 1962 of event 10, there was a detailed description of the environment of a bus in which TB was transmitted extensively from a school bus driver to students [17]. The bus was equipped with two fan heaters, one situated to the left beside the bus driver and the other midway in the bus. There was a defroster at the base of the windscreen and two fans were installed (one on either side of and directed at the 
windscreen). When in use, those would move air from the front to the rear of the bus.

An investigation on CT related to bus drivers with pulmonary TB (event 11) provides some information on potential environmental factors [24]. Even though the extent of ventilation in all buses was not known, it was seen as likely that the windows were closed due to wintertime. However, according to the school policy, the driver (with pulmonary TB) was not allowed to let the children off when the bus had arrived early. Therefore, the children waited on the bus with the driver for 15-20 minutes (in addition to a trip duration of 25-35 minutes), during which time the windows remained closed. This may have contributed to prolonged cumulative exposure of the students in a poorly ventilated environment. No information concerning the seating of the children on the buses was provided. It was not possible to draw any conclusion regarding seat position and exposure.

\section{Discussion and conclusions}

Our review of the scientific literature revealed 14 events (15 publications) of documented human-to-human transmission of airborne infectious disease related to public ground transport. Most of the scientific publications we selected report on transmission of TB, a few on meningococcal disease and one on measles: reports on transmission of other pathogens are lacking. In our review we address various factors potentially influencing disease transmission such as length of exposure, proximity to index case and type of ventilation. Complementary to the review of scientific literature, we conducted a web-based search of non-scientific literature in order to ensure a broader search and to assess the potential for publication bias. Through the non-scientific literature search we identified eight events, two of which were reported in the scientific literature, but only one of them [19] was picked up by our scientific literature search.

Close to half a billion citizens in the 27 countries of the European Union enjoy access to various means of transportation [1]. Given the large number of passengers travelling by public ground transport, the number of reported incidents appears to be very low $[1,2]$. The anonymous nature of contact between passengers makes it unlikely that an infectious disease diagnosed after a trip will trigger warnings or investigations with reference to travel-related exposure, unless unusual circumstances such as 'dramatic' illness (e.g. loss of consciousness in meningococcal disease) are involved. The lack of evidence of disease transmission related to use of public ground transport and the lack of guidance documents may be reasons for the limited number of publications in this field.

The World Health Organization guidelines for air travel recommend $C T$ of passengers exposed to people with pulmonary TB who sat in adjacent rows for longer than eight hours (including ground delays) $[46,47]$. These guidelines refer to single trips whereas in public ground transport, repeated (daily) and short trips to and from school or the workplace, for example, also take place.

Cumulative exposure related to repeated bus trips can lead to high transmission rates of TB and to transmission of meningococcal disease. We identified reports describing an association between the duration of exposure to TB through repeated trips and seroconversion in contact persons (Table 2): generally speaking, the longer the travel duration, the higher the rate of seroconversion $[16,17]$.

Environmental characteristics such as space and air (re)circulation may influence the risk of disease transmission. It is known that droplet nuclei may be transported through ventilation systems, as has been documented for TB [48]. Indoors, bacilli are potentially trapped, disperse within a room, and may remain viable and suspended in the air for a prolonged period of time [49-52]. Dilution of infectious particles through local air circulation and overall room ventilation can direct exposure into spaces that were not even visited by the index patient [53-56]. Comprehensive information on factors potentially influencing the risk of disease transmission is lacking for travel in public ground conveyances. Detailed information on ventilation and air circulation has been given in two publications: however, the factors were not systematically evaluated $[17,19]$. Given the low number of publications dedicated to infectious disease transmission and ventilation systems, we included studies dating back to the $1960 \mathrm{~s}$ when air conditioning systems were not commonly in use on buses. Findings based upon older studies might therefore not be applicable to newer systems.

Crowding of passengers in public or school buses may act as a triggering factor on the transmission of TB and meningococcal disease $[16,26]$. Transmission through brief but intensive contact has been described for TB [57-62]. In a cohort study with a random sample of 142 commuters on the association between public commuter transport in Peru and pulmonary TB in workers, the authors concluded that the use of minibuses increased the risk of pulmonary TB due to overcrowding, cumulative exposure to persons with productive coughs while commuting twice daily five days a week, closed windows on minibuses, combined with a high prevalence of pulmonary TB [63]. Furthermore, persons with pulmonary TB have more productive coughs in the mornings, hence increasing the risk for transmission of TB to other passengers presumably during morning travel [64], as has already been suggested by other studies in developing and industrialised countries $[16,65,66]$. While it is recognised that overcrowding in confined spaces increases the risk of transmission, this risk has not been quantified [64]. Not only in settings such as public transport, the relation between overcrowding, duration of exposure including cumulative exposure, ventilation and other environmental 
characteristics and disease transmission remains poorly understood.

CT after potential disease transmission in public ground transport is hampered by logistic hurdles. The follow-up of passengers, especially in urban settings, is unfeasible or, at best, limited since passenger data (e.g. name, telephone number, email address), in metros, trams and short-distance bus trips are mostly not collected. Anonymous transport seems to be one of the main hurdles for the initiation of CT. If passenger data are indeed collected, limited storage, lack of useful data, transport company policies and accessibility of data may be further obstacles.

In national long-distance or international railway or bus trips, passenger data may also not be collected routinely. We identified only one scientific publication where $\mathrm{CT}$ was performed on the basis of passenger lists for a single railway trip [13]. Without passenger data, CT has to rely on media appeals to inform potentially affected co-passengers. A case of invasive meningococcal disease with fatal outcome in a Swiss student visiting Berlin (Germany) on a class trip by train in 2008 demonstrates the ability to identify contacts in an anonymous transport system [44]. Since no passenger data were collected, it was decided to perform CT through a press release informing the public about meningococcal disease. It also asked the woman who had travelled in the same train compartment as the patient to contact the local health department to receive chemoprophylaxis, which she did.

Contact investigations require a substantial amount of financial and human resources. In none of the retrieved studies was the cost of CT provided nor was the effectiveness of interventions to prevent the transmission of infectious diseases evaluated. Concerning air travel, two publications report on the cost of investigations related to the estimated number of passengers with TB $[67,68]$. The authors concluded that in the case of TB, contact investigations in aircrafts are highly inefficient. Nevertheless, CT in air travel receives a high level of attention, which is reflected in international regulations and recommendations [46,47]. Taking into account the substantial logistic hurdles, it seems likely that $\mathrm{CT}$ after exposure to infectious diseases in public ground transport is inefficient.

All selected contact investigations attempted to discriminate between contact persons infected while travelling with the index case and transmission in other settings, e.g. schools or workplaces. Some investigations may demonstrate stronger evidence than others: in some, contacts were clearly limited to a bus since the index case was a bus driver $[17,19,24]$, while other reports identified bus transport as an independent risk factor through multivariate analysis $[14,16]$. Conclusions that can be drawn from most of the identified $C T$ investigations are limited by the small number of exposed individuals. A few publications, however, provide some evidence due to a relatively high number of tested contact persons $[13,16,17]$.

Evidence on transmission of infectious diseases is limited by the quantity and quality of the reported CT studies. The publications we selected describe observational studies, which lack a control group and an attempt to minimise bias. Most of the investigations we selected were related to cumulative exposure in school buses where CT was obviously feasible. Only three relevant publications on single-trip exposure were found. Further we could locate only one publication describing CT following a railway trip [13]. The transmission rates may underestimate or conversely overestimate the actual transmission rates since not all contact persons were traced. Concerning the only publication on CT following travel of a TB case on a single railway trip, the train operator's records allowed $77 \%$ of all passengers on the trip to be located. However, only $49 \%$ of located passengers were evaluated, hence the possibility of more extensive transmission cannot be excluded.

The lack of evidence on disease transmission in public ground transport as well as logistic hurdles related to $\mathrm{CT}$ may be the main reasons for the limited number of relevant publications we could identify. We assume that transmission of airborne infectious diseases in public ground transport takes place but does not result in scientific publications, or reports do exist but have not been published. Thus the risk of infectious disease transmission as well as the public health impact of transmission of airborne communicable diseases during travel in railways or buses/coaches remains largely unknown. Even though the risk of infectious disease transmission in ground transport may be higher than in air transport, our investigations did not generate evidence that transmission of infectious diseases in public ground transport is an issue of great public health importance. Taking into account the logistic hurdles and probably limited effectiveness of CT, we conclude that only circumstances such as dramatic illness or organised trips would justify CT in public ground transport. This contrasts with the high profile CT of air passengers has in international regulations and recommendations and raises the question whether indications for CT should be revisited after a risk- benefit assessment and a comprehensive analysis taking into account exposures in both ground and air transport. 


\section{Acknowledgments}

We thank the following experts and colleagues for sharing their knowledge and judgement for this work: Philip Monk (Health Protection Agency (HPA), Local and Regional Services, United Kingdom), Corien Swaan (National Institute for Public Health and the Environment (RIVM), the Netherlands), Udo Goetsch (Frankfurt Department of Health, Germany), René Gottschalk (Frankfurt Department of Health, Germany), Daniel Menucci (International Health Regulations Coordination WHO Lyon Office, France) and Lindsey Barr (International Association of Public Transport, Belgium).

This publication arises from the project REACT (Response to Emerging infectious diseases: Assessment and development of Core Capacities and Tools) which has received funding from the European Union, in the framework of the Public Health Programme (funding number 2007211).

\section{References}

1. Eurostat. Panorama of Transport. Luxembourg: Office for Official Publications of the European Communities, 2009. Available from: http://epp.eurostat.ec.europa.eu/cache/ITY OFFPUB/KS-DA-09-001/EN/KS-DA-09-001-EN.PDF

2. Askar M, Mohr O, Eckmanns T, Krause G, Poggensee G. Quantitative assessment of passenger flows in Europe and its implications for tracing contacts of infectious passengers. Euro Surveill. 2012;17(24):pii=20195. Available from: http://www. eurosurveillance.org/ViewArticle.aspx?Articleld=20195

3. Australasian Society for HIV Medicine (ASHM). Australasian Contact Tracing Manual. Darlinghurst: ASHM; 2011. Available from: http://www.ashm.org.au//images/Publications/ Monographs/ctm/ctm_2010.pdf

4. Centers for Disease Control and Prevention (CDC). Public Health Guidance for Community-Level Preparedness and Response to Severe Acute Respiratory Syndrome (SARS) Version 2/3* - Supplement E: Managing International travelrelated transmission risk. Atlanta: CDC;2004. Available from: http://www.cdc.gov/sars/guidance/E-travel/index.html

5. Edelson PJ, Phypers M. TB transmission on public transportation: a review of published studies and recommendations for contact tracing. Travel Med Infect Dis. 2011;9(1):27-31.

6. Falagas ME, Pitsouni El, Malietzis GA, Pappas G. Comparison of PubMed, Scopus, Web of Science, and Google Scholar: strengths and weaknesses. FASEB J. 2008;22(2):338-42.

7. Burnham JF. Scopus database: a review. Biomedical Digit Libr. 2006;3:1.

8. SciVerse Scopus. Content Coverage Guide, May 2012. [Accessed 17 Jul 2012]. Available from: http://www.info. sciverse.com/scopus/scopus-in-detail/facts

9. Centers for Disease Control and Prevention (CDC). Measles (Rubeola), 2010 Case Definition. [Accessed 15 Aug 2012]. Available from: http://www.cdc.gov/osels/ph_surveillance/ nndss/casedef/measles_2010.htm

10. Linnemann CC Jr, Rotte TC, Schiff GM, Youtsey JL. A seroepidemiologic study of a measles epidemic in a highly immunized population. Am J Epidemiol. 1972;95(3):238-46.

11. Chen RT, Markowitz LE, Albrecht P, Stewart JA, Mofenson LM, Preblud SR, et al. Measles antibody: reevaluation of protective titers. J Infect Dis. 1990;162(5):1036-42.

12. Edmonson MB, Addiss DG, McPherson JT, Berg JL, Circo SR, Davis JP. Mild measles and secondary vaccine failure during a sustained outbreak in a highly vaccinated population. JAMA. 1990;263(18):2467-71.

13. Moore M, Valway SE, Ihle W, Onorato IM. A train passenger with pulmonary tuberculosis: Evidence of limited transmission during travel. Clin Infect Dis. 1999;28(1):52-6.

14. Extremera Montero F, Moyano Acost R, Gómez Pozo B, Bermudez Ruiz P, Lopez Mendez J, Aguilar Rivas S, et al. Exposición a Mycobacterium tuberculosis durante un viaje en autobús. [Exposure to Mycobacterium tuberculosis during a bus travel]. Med Clin (Barc). 2001;116(5):182-5. Spanish.

15. Helfand RF, Kim DK, Gary HE, Jr, Edwards GL, Bisson GP, Papania MJ, et al. Nonclassic measles infections in an immune population exposed to measles during a college bus trip. J Med Virol. 1998;56(4):337-41.

16. A school- and community-based outbreak of Mycobacterium tuberculosis in northern Italy, 1992-3. The Lodi Tuberculosis Working Group. Epidemiol Infect. 1994;113(1):83-93.

17. Rogers EF. Epidemiology of an outbreak of tuberculosis among school children. Public Health Rep. 1962;77:401-9.

18. Curtis AB, Ridzon R, Vogel R, Mcdonough S, Hargreaves J, Ferry J et al. Extensive transmission of Mycobacterium tuberculosis from a child. N Engl J Med. 1999;341(20):1491-5.

19. Neira-Munoz E, Smith J, Cockcroft P, Basher D, Abubakar I. Extensive transmission of Mycobacterium tuberculosis among children on a school bus. Pediatr Infect Dis J. 2008;27(9):835-7.

20. Phillips L, Carlile J, Smith D. Epidemiology of a tuberculosis outbreak in a rural Missouri high school. Pediatrics. 2004;113(6):e514-9.

21. Sacks IJ, Brenner ER, Breeden DC. Epidemiology of a tuberculosis outbreak in a South Carolina junior high school. Am J Public Health. 1985;75(4):361-5.

22. Yagi T, Sasaki Y, Yamagishi F, Mizutani F, Wada A, Kuroda F. [Tuberculosis microepidemic in a commuter bus.] Kekkaku. 1999;74(6):507-11. Japanese.

23. Mahady SC. An outbreak of primary tuberculosis in school children. Clinical aspects. The Am Rev Respir Dis. 1961;84:348-58.

24. Yusuf HR, Braden CR, Greenberg AJ, Weltman AC, Onorato IM, Valway SE. Tuberculosis transmission among five school bus 
drivers and students in two New York counties. Pediatrics. 1997;100(3): E9.

25. Darney PD, Clenny ND. Tuberculosis outbreak in an Alabama High School. JAMA. 1971;216(13):2117-8.

26. Beard FH, McAnulty JM, Tapsall JW, Zaia AM. Probable transmission of meningococcal disease on a school bus. Med J Aust. 2006;184(2):90.

27. Harrison LH, Armstrong CW, Jenkins SR, Harmon MW, Ajello GW, Miller GB Jr, et al. A cluster of meningococcal disease on a school bus following epidemic influenza. Arch Intern Med. 1991;151(5):1005-9.

28. Foster P. Schoolchildren catch TB from the school bus. Portsmouth Evening News. 2007 Jun 14. Available from: http:// www.portsmouth.co.uk/newshome/Schoolchildren-catch-TBfrom-the.2956899.jp

29. Knapp M. School bus driver sparks TB alert. The Express on Sunday. 2007 Jun 17.

30. Givens M. Chelmsford TB case sparks student tests. Boston Herald. 2007 Nov 6. Available from: http://pqasb.pqarchiver. com/bostonherald/access/1378350841.html?FMT=ABS\&FMTS= ABS:FT\&date $=$ Nov $+6 \% 2 \mathrm{C}+2007 \&$ author $=$ MICHAEL+GIVENS\&pu $\mathrm{b}=$ Boston + Herald\&edition $=\&$ startpage $=14 \&$ des $=$ Chelmsford + $\mathrm{TB}+$ case+sparks+student+tests

31. Fargen J. Boston-to-Montreal bus passengers warned of TB exposure. Boston Herald. 2007 Jul 25. Available from: http://news.bostonherald.com/news/regional/view. bg?articleid $=1013213$

32. Reuters. Canada Greyhound bus passengers exposed to TB. Ottawa Citizen. 2008 Oct 2. Available from: http://www2.canada.com/ottawacitizen/news/story html id =9577e658-f557-4d1a-b23a-463d7adbcec6\&k=90453

33. Satyanarayana M. Canada seeks 27 Detroit-bound bus passengers as TB precaution. Financial Times. 2008 Oct 2.

34. Puzic S. Canwest news service: Woman with TB sparks search for bus riders. Test recommended for passengers who got off in Windsor on Aug. 31. Ottawa Citizen. 2008 Oct 3.

35. CTV Globemedia. Officials fear Greyhound passengers exposed to TB. 2008 Oct 2. Available from: http://toronto.ctvnews.ca/ officials-fear-greyhound-passengers-exposed-to-tb-1.330363

36. Doran J. Hunt for rush-hour commuters exposed to sick nurse; Canada; Sars. The Times. 2003 Apr 22. Available from: http://www.thetimes.co.uk/tto/public/sitesearch. do?querystring=Hunt+for+rush-hour+commuters+exposed+to+ sick+nurse \& $p=t$ to \&pf $=$ all \&bl=on

37. Warren M. Search for passengers on virus train. The Daily Telegraph. 2003 Apr 22. Available from: http://www.telegraph. co.uk/news/worldnews/asia/china/1428138/Search-forpassengers-on-virus-train.html

38. Fünf neue Fälle von Meningitis: Fernzug unter Quarantäne gestellt. [Five new cases of meningitis: train quarantined]. Frankfurter Allgemeine Zeitung. 1998 Mar 9. German. Available from: http://www.seiten.faz-archiv.de/faz/19980309/ f19980309mening-100.html

39. Euro City Michelangelo nach Meningitis Fall unter Quarantäne gestellt. Dramatische Szenen auf dem Bahnhof Rosenheim. Lehrerin rettet durch entschlossenes Handeln akut erkranktem Schüler das Leben. Keine weiteren Ansteckungsfälle. [Euro City train Michelangelo placed under quarantine after meningitis case. Dramatic scenes at the Rosenheim station. Teacher rescues acutely diseased student's life through decisive action. No further cases of infection]. Süddeutsche Zeitung 1998 Sep 3. German.

40. Nach Meningitis-Fall kam Eurocity unter Quarantäne. Neue Erkrankungen in Bayern und Rheinland-Pfalz. [Euro City train under quarantine after a case of meningitis: New cases in Bavaria and Rhineland Palatinate]. Frankfurter Rundschau 1998 Sep 3. German.

41. Dritter Meningitis-Fall in Berlin. [Third case of meningitis in Berlin]. Die Zeit. 2008 Oct 24. German. Available from: http:// www.zeit.de/news/artikel/2008/10/24/2644037.xml

42. Berlin-Besucherin an Hirnhautentzündung verstorben. [Berlin visitor died of meningitis]. Der Tagesspiegel. 2008 Oct 21. German. Available from: http://www.tagesspiegel. de/berlin/berlin-besucherin-an-hirnhautentzuendungverstorben/1353356.html

43. Gesundheitsverwaltung schaltet Krisentelefon. [Health authorities sets up crisis telephone]. Der Tagesspiegel. 2008 Oct 22. German. Available from: http://www.tagesspiegel.de/ berlin/gesundheitsverwaltung-schaltet-krisentelefon/1354316. html

44. Zuschneid I, Witschi A, Quaback L, Hellenbrand W, Kleinkauf N, Koch D, Krause G. Invasive meningococcal disease with fatal outcome in a Swiss student visiting Berlin. Euro Surveill. 2008;13(45): pii=19031. Available from: http://www. eurosurveillance.org/ViewArticle.aspx?Articleld =19031
45. Rust S, Kissinger M. 700 exposed to rubella patient: Woman rode to downtown office on Freeway Flyer. Milwaukee Journal Sentinel. 2008 Apr 30. Available from: www.jsonline.com/ story/index.aspx?id $=745266$

46. World Health Organization (WHO). Tuberculosis and air travel: guidelines for prevention and control. 3 rd ed. Geneva: WHO, 2008. Available from: http://www.who.int/tb/ publications $/ 2008 /$ WHO HTM TB 2008.399 eng.pdf

47. World Health Organization (WHO). Tuberculosis and air travel: Guidelines for prevention and control. 2nd ed. Geneva: WHO; 2006. Available from: http://whqlibdoc.who.int/hq/2006/ WHO_HTM_TB_2006.363_eng.pdf

48. Li Y, Leung GM, Tang JW, Yang X, Chao CY, Lin JZ, et al. Role of ventilation in airborne transmission of infectious agents in the built environment - a multidisciplinary systematic review. Indoor Air. 2007;17(1):2-18.

49. Wells WF, Stone WR. On air-borne infection. Study III. Viability of droplet nuclei infection. Am J Hyg. 1934;20:619-27.

50. Riley RL. Airborne infection. Am J Med. 1974;57(3):466-75.

51. Nardell EA. Catching droplet nuclei: toward a better understanding of tuberculosis transmission. Am J Respir Crit Care Med. 2004;169(5):553-4.

52. Fennelly KP, Martyny JW, Fulton KE, Orme IM, Cave DM, Heifets LB. Cough-generated aerosols of Mycobacterium tuberculosis: a new method to study infectiousness. Am J Respir Crit Care Med. 2004;169(5):604-9.

53. Rieder HL. Risk of travel-associated tuberculosis. Clin Infect Dis. 2001;33(8):1393-6.

54. Houk VN, Baker JH, Sorensen K, Kent DC. The epidemiology of tuberculosis infection in a closed environment. Arch Environ Health. 1968;16(1):26-35.

55. Stead WW. Management of health care workers after inadvertent exposure to tuberculosis: a guide for the use of preventive therapy. Ann Intern Med. 1995;122(12):906-12.

56. Houk VH, Kent DC, Baker JH, Sorensen K, Hanzel GD. The Byrd study. In-depth analysis of a micro-outbreak of tuberculosis in a closed environment. Arch Environ Health. 1968;16(1):4-6.

57. Diel R, Seidler A, Nienhaus A, Rusch-Gerdes S, Niemann S. Occupational risk of tuberculosis transmission in a low incidence area. Respir Res. 2005;6:35.

58. Bauer J, Kok-Jensen A, Faurschou P, Thuesen J, Taudorf E, Andersen $A B$. A prospective evaluation of the clinical value of nation-wide DNA fingerprinting of tuberculosis isolates in Denmark. Int J Tuberc Lung Dis. 2000;4(4):295-9.

59. Golub JE, Cronin WA, Obasanjo O0, Coggin W, Moore K, Pope DS, et al. Transmission of Mycobacterium tuberculosis through casual contact with an infectious case. Arch Intern Med. 2001;161(18):2254-8.

6o. Raffalli J, Sepkowitz KA, Armstrong D. Communitybased outbreaks of tuberculosis. Arch Intern Med. 1996;156(10):1053-60.

61. Lincoln EM. Epidemics of tuberculosis. Bibl Tuberc. 1965;21:157-201.

62. Rich RA. The Pathogenesis of Tuberculosis. JAMA. 1952;148(14).

63. Horna-Campos OJ, Sánchez-Pérez HJ, Sánchez I, Bedoya A, Martín M. Public transportation and pulmonary tuberculosis, Lima, Peru. Emerg Infect Dis. 2007;13(10):1491-3.

64. Beggs CB, Noakes CJ, Sleigh PA, Fletcher LA, Siddiqi K. The transmission of tuberculosis in confined spaces: an analytical review of alternative epidemiological models. Int J Tuberc Lung Dis. 2003;7(11):1015-26.

65. Rojas RA. Brotes de tuberculosis en niños que usaban autobus escolar. http://mazinger.sisib.uchile.cl/repositorio/ lb/ciencias_quimicas_y_farmaceuticas/armijor/cap9/ tuberculosis.html

66. Human infection with new influenza $A\left(\mathrm{H}_{1} \mathrm{~N}_{1}\right)$ virus: WHO Consultation on suspension of classes and restriction of mass gatherings to mitigate the impact of epidemics caused by influenza A ( $\left.\mathrm{H}_{1} \mathrm{~N}_{1}\right)$, May 2009. Wkly Epidemiol Rec. 2009;84(27):269-71. English, French.

67. Vassiloyanakopoulos A, Spala G, Mavrou E, Hadjichristodoulou C. A case of tuberculosis on a long distance flight: the difficulties of the investigation . Euro Surveill. 1999;4(9):pii=83. Available from: http://www.eurosurveillance. org/ViewArticle.aspx?Articleld $=83$

68. McFarland JW, Hickman C, Osterholm M, MacDonald KL. Exposure to Mycobacterium tuberculosis during air travel. Lancet. 1993;342(8863):112-3. 